\title{
A case of acute compartment syndrome of the leg following prolonged lithotomy position during urological surgery
}

\author{
Chetan Prakash, Abdullah A Bonajmah, Amro Ahmed
}

\begin{abstract}
Introduction: Acute compartment syndrome (ACS) is an orthopedic emergency which if not recognized and treated in time can lead to serious irreversible damage to neuromuscular structures. Case Report: We are reporting here a case of acute compartment syndrome of the right leg in an adult male patient following a prolonged urological surgery of five hours in the lithotomy position. Post-operatively the patient's signs and symptoms were diagnosed early and an urgent fasciotomy was done which relieved him of his symptoms and averted major damage to his leg. Conclusion: Acute compartment syndrome of the leg is a recognized but rare iatrogenic complication in many prolonged urological procedures due to lithotomy position used in them. If prolonged urological procedure is necessary patient should be monitored post operatively for early and prompt treatment of this complication. Early diagnosis and prompt treatment is the main-stay of the treatment in cases of acute compartment syndrome following unavoidable prolonged urological procedures in lithotomy position. We recommend a written consent and
\end{abstract}

Chetan Prakash ${ }^{1}$, Abdullah A. Bonajmah ${ }^{1}$, Amro Ahmed ${ }^{1}$ Affiliations: ${ }^{1}$ Orthopedic Surgeon, Ward -20, Department of Orthopedic Surgery, Farwaniya Hospital, Kuwait. Corresponding Author: Dr. Chetan Prakash, Orthopedic Surgeon, Ward - 20, Department of Orthopedic Surgery Farwaniya Hospital, Kuwait; Ph: 00965-66540312, 00965-24890198, Email: drcprakash@hotmail.com

Received: 06 May 2011

Accepted: 17 August 2011

Published: 01 October 2011 information to the patient regarding the risk of the above. In our case urgent decompression by four compartment fasciotomy was successful and averted all disabling complications.

Keywords: Orthopedic emergency, Acute compartment syndrome, Lithotomy position, Prolonged urological surgery

$* * * * * * * * *$

Prakash C, Bonajmah AA, Ahmed A. A case of acute compartment syndrome of the leg following prolonged lithotomy position during urological surgery. International Journal of Case Reports and Images 2011;2(9):19-22.

$$
* * * * * * * * *
$$

doi:10.5348/ijcri-2011-10-61-CR-5

\section{INTRODUCTION}

The original description of compartment syndrome was by Richard von Volkmann in 1872 [1]. He described contractures of the forearm muscles following tight bandaging for reduction of an elbow fracture. The contractures which resulted from ischemic muscle necrosis were later termed "Compartment Syndrome". Acute compartment syndrome is a painful condition, due to the pressure within the muscles that builds up to dangerous levels. This pressure can decrease blood flow, which prevents nourishment and oxygen from reaching the nerve and muscle cells. In this condition the perfusion pressure falls below the tissue pressure in a closed anatomic space, with subsequent compromise of tissue circulation and function. Acute compartment syndrome in patients undergoing prolonged urological/colorectal surgery is uncommon but can 
have catastrophic consequences for the patient with the development of metabolic acidosis, myoglobinuric renal failure, Volkmann's contracture, limb loss, and death $[2,3,4]$. The potential to produce long-term disability in a patient has important medico legal implications, particularly if the complication is avoidable. Why only some patients develop acute compartment syndrome is not fully understood.

\section{CASE REPORT}

A 36-year-old male patient was admitted with diagnosis of bulbar urethral stricture/recurrent urethral infection for more than 10 years and was operated by the urologist team. A urethroplasty was done in the lithotomy position (Figure 1) and the surgical time taken was about five hours The urologist was doing a arterial sparing urethroplasty which takes more time and is a demanding procedure.

Post-operatively the patient complained of pain and swelling in the right calf muscles (Figure 2). Ultrasound-Doppler study was done which ruled out deep vein thrombosis. Orthopedic surgeon was then called and during examination the patient had severe stretch pain. He was not able to dorsiflex the right ankle and sensory loss over the right foot was found. Dorsalis pedis and posterior tibial artery pulses were palpable but weak. An immediate diagnosis of acute compartment syndrome was made. Patient was urgently taken to the operation theatre and a four compartment fasciotomy of the right leg was done (Figure 3). Also we did an intra-compartment pressure measurement which was $33 \mathrm{mmHg}$ by Whiteside's technique. Intra-operatively tight fascia and severe muscular swelling was found in the right leg. We made a single longitudinal, lateral incision in line with the fibula, extending from just distal to the head of the fibula to 3-4 $\mathrm{cm}$ proximal to the lateral malleolus. A longitudinal fasciotomy of the anterior and lateral compartments was performed. The skin was undermined posteriorly and a fasciotomy of the superficial posterior compartment was performed. The interval between the superficial and lateral compartments distally was developed proximally by detaching the soleus from the fibula. The fascial attachment of the tibialis posterior muscle to the fibula was identified and this fascia was incised longitudinally. Patient was relieved of his symptoms post-operatively. The fasciotomy wound was left open and was later grafted by the plastic surgeon (Figure 4). Post operative laboratory values were: total WBC count $-15100 / \mathrm{mm}^{3}$, Neutrophils - 73\%, $\mathrm{pH}-7.49, \mathrm{pCO} 2-$ $5.3 \mathrm{mmHg}, \mathrm{pO} 2$ - $29.1 \mathrm{mmHg}$. Blood urea and creatinine were normal. On his last follow up patient had regained good power of dorsiflexion of his ankle and his sensations of the foot has also improved.

\section{DISCUSSION}

Different factors play the role in development of

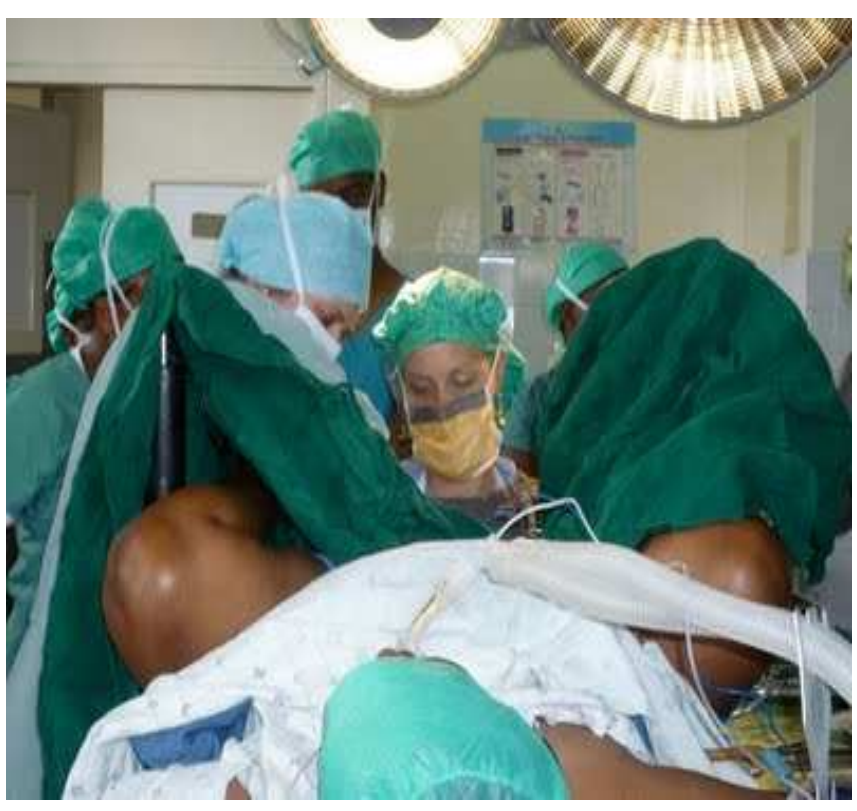

Figure 1: Lithotomy position during a urological surgery.

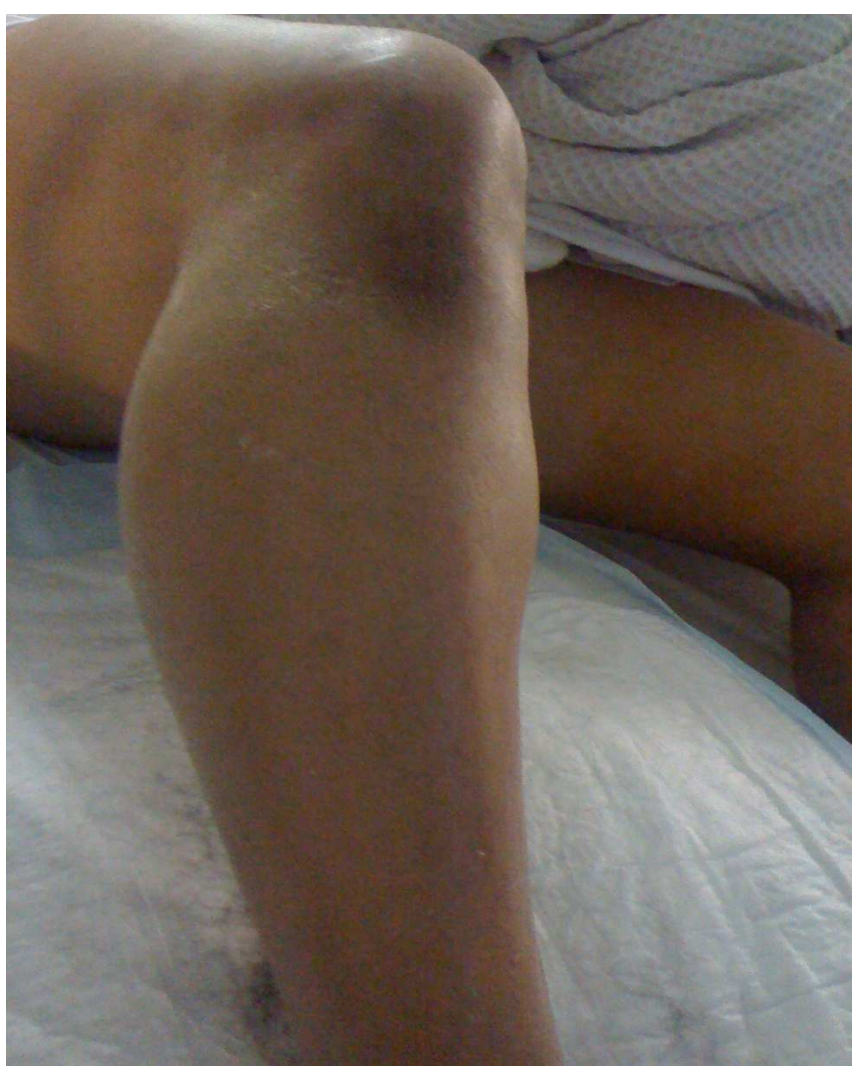

Figure 2: Gross swelling of right leg pre-operatively.

compartment syndrome: lithotomy position (with or without head down), ankle and knee position, external compression prophylaxis for deep vein thrombosis, method of leg support used, duration of surgery and 


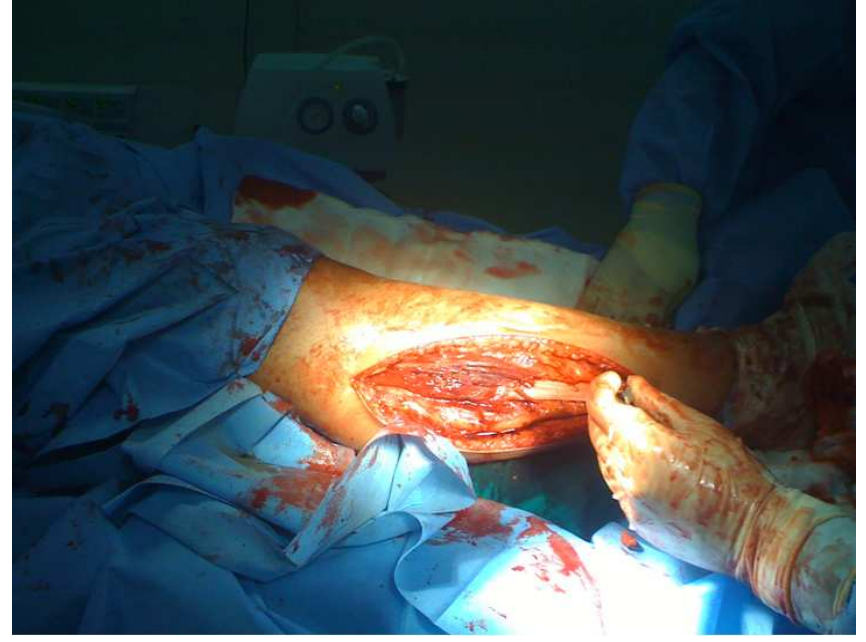

Figure 3: Single incision fasciotomy of the right leg - intraoperative picture showing gross muscle bulge.

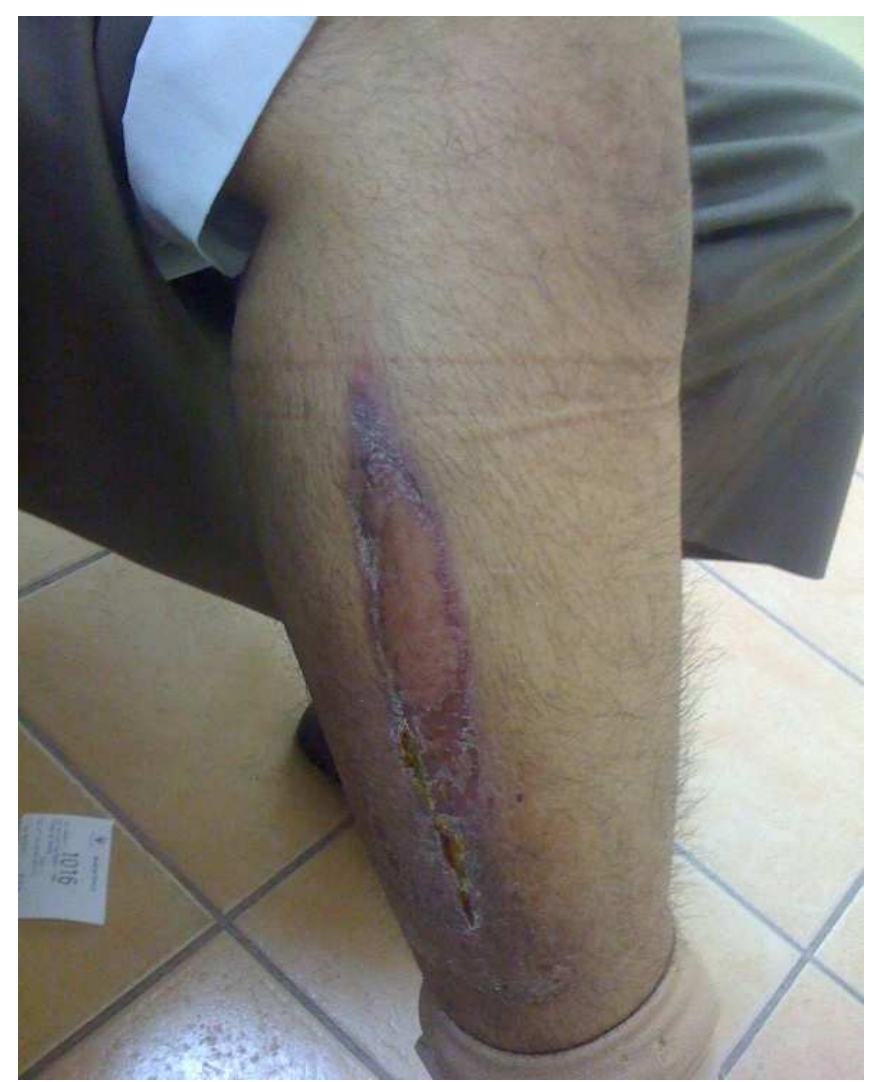

Figure 4: Three and half months post operatively after skin graft of the right leg.

physiologic factors, such as gender, age, and body mass index. All efforts should be directed to prevent the establishment of acute compartment syndrome and there are accepted methods, such as limiting the time of leg elevation, positioning the leg below the level of the atrium and postoperative monitoring of patients at risk $[5,6]$. There is still a debate on the intra-operative use of pulse oximetry to detect hypoperfusion and the appropriate use of sequential compression devices and anti-thromboembolic stockings. There is an increased intramuscular pressure due to external compression from the calf support and decreased perfusion pressure due to the elevated position. This causes a significant decrease in the difference between the diastolic blood pressure and the intramuscular pressure when the leg is placed in the hemi-lithotomy position in a well-leg holder. Thus combined with prolonged surgical time, this position may cause an acute compartment syndrome of the leg. In the setting of classical presentation of compartment syndrome and physical examination findings, no further diagnostic workup is needed.

No consensus exists regarding the pressure for which fasciotomy should be performed. Whitesides et al. noted that fasciotomy should be performed when compartment pressure rises to within $10-30 \mathrm{mmHg}$ of the patient's diastolic blood pressure (this value has been coined the $\Delta \mathrm{P}$ ) [7]. McQueen et al. studying compartment syndrome in dogs, affirmed the difference of $30 \mathrm{mmHg}$ between the compartment pressure and the diastolic blood pressure as a more reliable measure than absolute pressure measurements [8]. Many surgeons now use the measured compartment pressure of $30 \mathrm{~mm} \mathrm{Hg}$ as a indication for fasciotomy.

Multiple pressure readings are often obtained, and the clinician must decide how to incorporate these readings in the clinical picture and in decision-making process. Pfeffer et al. showed that the lithotomy position is associated with changes in intracompartment pressure that are dependent on the method of leg support used [4]. Furthermore, they indicate that intermittent external compression can reduce intra-compartment pressure in the lower leg. Therefore, increase in intra-compartment pressure during surgery in the lithotomy position with the calf or knee supported may be one of the factors that contribute to the development of compartment syndrome. Further, use of intermittent external compression may significantly reduce this increase in pressure [9, 10]. The etiology of compartment syndrome is multifactorial and prevention should be the mainstay of treatment. With significant morbidity and mortality, in particular lower limb morbidity secondary to fasciotomy wounds and long term neurological sequel, all urologists should be aware of this iatrogenic complication and how to prevent or treat it when it occurs $[11,12]$. While positioning the legs, it is important to ensure that the lower legs are lifted only slightly above left atrial level. Creatine kinase values over 2,000 U/L (when rhabdomyolysis occurs, serum creatine kinase activity increases) after surgery may be considered a warning sign in ventilated and sedated patients, in whom early clinical symptoms of the compartment syndrome such as pain and paresthesias cannot be ascertained. Frequent and 
regular checks of these parameters starting shortly after surgery are recommended. An epidural anesthesia bears the risk of a protracted diagnosis.

\section{CONCLUSION}

Acute compartment syndrome is a preventable condition after prolonged urological procedures in the lithotomy position. Patients should be carefully monitored after urological procedures. In case of suspected compartment syndrome we recommend early fasciotomy in order to avoid irreversible damage to the limbs. More research is required to set clear guidelines on patient's positioning during surgery.

$* * * * * * * * *$

\section{Author Contributions}

Chetan Prakash - Conception and design, Acquisition of data, Analysis and interpretation of data, Drafting the article, Critical revision of the article, Final approval of the version to be published

Abdullah A. Bonajmah - Conception and design, Analysis and interpretation of data, Drafting the article, revision of the article, Final approval of the version to be published

Amro Ahmed - Substantial contributions to conception and design, Acquisition of data, Analysis and interpretation of data, Drafting the article, Critical revision of the article, Final approval of the version to be published

\section{Guarantor}

The corresponding author is the guarantor of submission.

\section{Conflict of Interest}

Authors declare no conflict of interest.

\section{Copyright}

(C) Chetan Prakash et al. 2011; This article is distributed under the terms of Creative Commons attribution 3.0 License which permits unrestricted use, distribution and reproduction in any means provided the original authors and original publisher are properly credited. (Please see www.ijcasereportsandimages.com /copyright-policy.php for more information.)

\section{REFERENCES}

1. Von Volkmann R. Die Ischamischen muskelahmungenund kontrakturen. Zentralbl Chir. 1881,8,801-3.

2. Raza A, Byrne D, Townell N.Review Lower limb (well leg)Compartment syndrome after urological pelvic surgery. J Urol. 2004;171(1):5-11.

3. Bergqvist D, Bone $\mathrm{M}$, Ekelund $\mathrm{G}$, et al.
Compartment syndrome after prolonged surgery with leg supports. Int J Colorectal Dis. 1990;5:1-5.

4. Pfeffer SD, Halliwill JR, Warner MA Effects of lithotomy position and external compression on lower leg muscle compartment pressure. Anesthesiology. 2001;95:632-6.

5. Khalil I. Bilateral compartmental syndrome after prolonged surgery in the lithotomy position. J Vasc Surg. 1987;5:879-81.

6. Lampert R, Weih EH, Breucking E, Kirchhoff S, Lazica B, Lang $\mathrm{K}$ Postoperative bilateral compartment syndrome resulting from prolonged urological surgery in lithotomy position. Serum creatine kinase activity (CK) as a warning signal in sedated, artificially respirated patients. Anaesthesist. 1995;44(1):43-7.

7. Whitesides TE, Heckman MM. Acute Compartment Syndrome: Update on Diagnosis and Treatment. J Am Acad Orthop Surg. 1996 Jul;4(4):209-18.

8. McQueen MM, Court-Brown CM. Early diagnosis of compartment syndrome: continuous pressure measurement or not? Injury. 2010 Apr;41(4):431-2.

9. Cohen SA, Hurt WG. Compartment syndrome associated with lithotomy position and intermittent compression stockings Obstet Gynecol. 2001;97:83;236.

10. Verdolin MH, Toth AS, Schroeder R. Bilateral lower extremity compartment syndrome following prolonged surgery in the low lithotomy position with serial 71 compression stockings. Anesthesiology. 2000;92:1189-92.

11. Mulhall JP, Drezner AD. Postoperative compartment syndrome and the lithotomy position: A report of three cases and analysis of potential risk factors. Conn Med. 1993;57:129-33.

12. Leff R, Shapiro S. Lower extremity complications of the lithotomy position: Prevention and management. J Urol. 1979;122:138-9. 